\title{
Téoros
}

Revue de recherche en tourisme

\section{Les congressistes sont des touristes. Bien sûr!}

\section{Normand Cazelais}

Volume 4, numéro 3, novembre 1985

L'essor de l'industrie des congrès

URI : https://id.erudit.org/iderudit/1080784ar

DOI : https://doi.org/10.7202/1080784ar

Aller au sommaire du numéro

Éditeur(s)

Université du Québec à Montréal

ISSN

0712-8657 (imprimé)

1923-2705 (numérique)

Découvrir la revue

Citer cet article

Cazelais, N. (1985). Les congressistes sont des touristes. Bien sûr! Téoros, 4(3),

3-3. https://doi.org/10.7202/1080784ar d'utilisation que vous pouvez consulter en ligne.

https://apropos.erudit.org/fr/usagers/politique-dutilisation/ 


\title{
Les congressistes sont des touristes. Bien sûr!
}

\author{
par Normand Cazelais *
}

\begin{abstract}
"Un bon representant de bureau de congres se tient tout a fait renseigne sur les ressources de sa localité pour les utiliser dans sa campagne de sollicitation. Ainsi, paysage, climat, circuits de wille et $d$ arriere-pays, restaurants, theatres, boites de nuit, grands magasins, artisanat, etc. sont des elements de base pour le vendeur. (...) I/ semble logique d'inclure dans lanalyse du produit, les activites existant dans le site considéré laspects commerclaux, culturels, artistiques, etc.). Le vendeur sait que les responsables du choix du site sont aussi d la recherche de l'inedít et $\|$ attache une importance toute particuliere a souhgner les attraits exclusifs de sa localité qui, sils sont bien présentés, peuvent souvent convaincre le client encore hésitant. "्ञा1
\end{abstract}

Le fait est connu: parmi les critéres de choix d'un site de congrès, compte tout

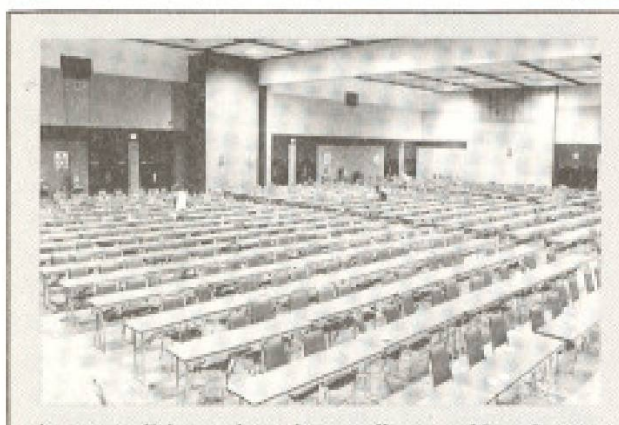

Les conditions dans lesquelles se déroule un congrés ne favorisent pas nécessairement une prise de contact avec la réalité du pays d'accueil et sa population.

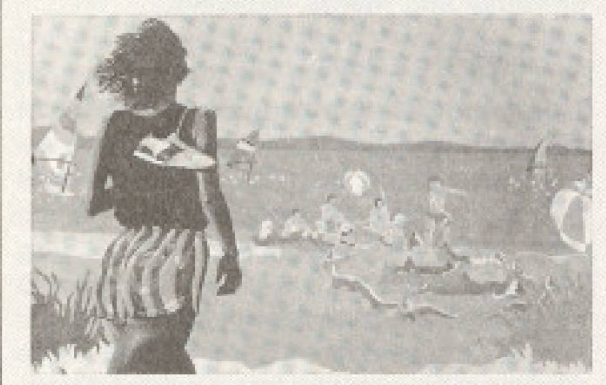

et cette habitude qu ont les congressistes. meme les plus sérieux, de ne pas assister a toutes les séances de travail et de faire "I'école buissonnière". autant - sinon davantage - la capacité d'attraction de sa localité, de la région ou du pays d'accueil que la nature et les caractéristiques des équipements des centres de congrès eux-mêmes. Ces derniers sont des pré-requis et, dans ce monde de constante et féroce compétition, ils doivent suivre et possiblement devancer l'évolution des besoins, des gouts et des techniques en la matière. Mais, pour emporter un choix, il faut plus et mieux: il faut un cadre. Ou, si vous voulez, une atmosphere, une ambiance, un décor.

Ceci est particulièrement évident dans le cas des "ligues majeures" où la concurrence s'exerce davantage entre les grandes villes touristiques de la planète (Paris, New York, Londres, Berlin, etc.) qu'entre leurs centres de congres respectifs: souvenezvous du Big Apple. A un cran inferieur, il faut également se rappeler le prestigieux prix de marketing (Canadian Marketing Golden Award) qu'a remporté en 1985 la Société du Palais des congrès de Montréal pour sa campagne de publicité de langue anglaise qui portait sur Montréal let non sur le Palais lui-même) et qui présentait la métropole sous un angle vraiment particulier, pour ne pas dire inédit ("Montreal, the most mischievous city").

Les centres de congrès situés ả l'extérieur des centres urbains, comme le Château Montebello, I'Estérel, le Mont-Sainte-Marie par exemple, n'échappent pas a la règle: leur publicité, si elle décrit toute la panoplie des ressources techniques dont peuvent profiter sur place les congressistes, s'attarde sur les "fringes benefits" (gymnases et salles d'exercice, piscines, saunas, cuisine, confort des chambres, golfs, plages ou pistes de ski à proximite, excursions dans les environs, etc. l qui, en fait, ne sont ni marginaux, ni secondaires. A preuve, ces établissements sont généralement des lieux de vacances, des destinations "touristiques", ce qu'on appelait autrefois des centres de villégiature, et que l'on qualifie aujourd'hui de "resorts". Car les congressistes, comme les vacanciers, sont des touristes.

\section{Une expérience comparable}

Comme le touriste, le congressiste, pour une période limitée, vit ailleurs, à l'extérieur de son quotidien. Comme le touriste, il consomme des services (restauration, hébergement, transport, détente, etc.) qui dédoublent ailleurs ceux de sa vie courante. Son emploi du temps et même son "travail" de congressiste sont différents de son horaire et de son travail réguliers. Par définition, le congressiste est dans une agora: il y rencontre d'autres personnes qui lui sont très souvent étrangères dans tous les sens du terme. Durant son "travail" de congressiste, dans un cadre qui n'est pas le sien (étranger, lui aussi), il échange avec elles, compare et parfois meme confronte ses idées, jugements et valeurs. Comme un touriste.

Tel un touriste "ordinaire" qui visite une usine, un musée ou une institution, le con= gressiste apprend â se familiariser, à travers la structure et le mode d'organisation d'un congrès et au cours de son déroulement, ả une façon de penser et de faire différente de chez lui: un congrès qui se tient à Chicoutimi ne se déroule pas comme a Montréal; à plus forte raison quand il a lieu au Japon, à Honolulu, en Italie ou encore à Winnipeg. Un congrès est un congrès, mais chacun ressemble, en fait, à l'endroit où il se tient.

D'autre part, les dépenses "de base" d'un congressiste lcouvrant le gite, les repas, le transport] sont déjả absorbées par un organisme payeur ou, sinon, déductibles d'impôts. Les commercants, tout comme les gouvernements, considèrent les congressistes comme des touristes très lucratifs car ceux-ci consacrent les sommes ainsi épargnées au chapitre des services de base -et meme davantage - a la poursuite d'activités dites "touristiques" Icircuits pré et post-congrès, achats de souvenirs, "night life", etc.). Sans parler de cette habitude très répandue qu'ont les congressistes - même les plus sérieux... - de ne pas assister à toutes les séances et activités de travail des congrès et de faire, bien ouil, l'école buissonière. Afin de mieux jouer les touristes. $f$

"Nomand Cazelais est chroniqueur touristique et membre du comité de rédaction de Téoros.

(1) Joseph L. Klein, Le monde des congrès, le 16 mars 1974. 